Beobachtung steht im Einklang mit MOORE (7), der eine Übereinstimmung der spezifischen Aktivität des Körperwassers feststellen konnte, das aus Urin, Blut und Atemwasser beim Menschen gewonnen wurde, denen HTO injiziert worden war. Danach hat sich beim Menschen ein Gleichgewicht des Tritiumgehaltes zwischen allen Körperflüssigkeiten spätestens nach etwa 1 Stunde eingestellt.

Durch das in Tabelle 1 dargestellte Ergebnis kann ferner eine bevorzugte Oxydation des Oestradiols durch das Nierenparenchym mit direkt anschließendem Austritt von HTO in den Urin vor Vermischen mit dem übrigen Körperwasser ausgeschlossen wërden, da dann der HTO- .
Spiegel im Urin höher sein müßte als im Serum. Aus den Werten für die männliche Versuchsperson in Tabelle 1 ergibt sich gegenüber den Fällen aus Abbildung 1 eine beschleunigte Oestradioloxydation, die dann auch zu einem höheren HTO-Spiegel im Körperwasser führte. Entsprechend mußte hier auch die beschleunigte Oestradioloxydation eine verminderte Ausscheidung von Oestradiol-17 $\alpha$-T oder von 17-Hydroxy-Derivaten festzustellen sein, was eine Untersuchung der Destillationsrückstände der Urinproben bestätigte.

Für fleißige Mitarbeit danken wir Fräulein Barbara HaNisCH und für materielle Unterstützung der Fa. Schering A. G., Berlin.

\title{
Literatur
}

1. Diczfalusy, E. und Cit. Lauritzen, Östrogene bei Menschen, Springer-Verlag, Berlin-Göttingen-Heidelberg (1961). - 2. RYAN, K. und L. ENGel, Endocrinology 52, 277 (1953). - 3. KAISER, E., W. Rindt und G. Oertel, Acta Hepato-Splenologica 12, 12 (1965). - 4. Breuer, H., R. KNUppen und M. Haupt, Nature (London) 212, 76 (1966). - 5. WeNZEL, M., H. KLEUCKer und E. P. SChulze, Z. Naturforsch. 21b, 1178 (1966). - 6. WENZEL, M. und E. KRAAS, Acta endocr., K'hvn. im Druck. - 7. MOORE, R.,
Health Physics 7, 161 (1962). - 8. Wenzel, M. und P. E. SCHulze, Tritium-Markierung, Walter de Gruyter \& Co., Berlin (1962): 9. Udekwu, F., D. Kozoll und K. Meyer, J. Nuclear Med. 4, 60 (1963). - 10. Fishiman, J., H. Bradlow, B. Zumoff, L. Hellman und T. Gallagher, Acta endocr. K'hvn 37, 57 (1961). - 11. Forster, D. und B. Bloom, J. biol. Chemistry 236, 2548 (1961). - 12. Wenzel, M., Habilitat. F. U. Berlin (1965). - 13. Hobermann, H., J. biol. Chemistry 233, 1045 (1958).

\section{Enzymatische Triglyceridbestimmungen bei Kindern}

\author{
Herrn Professor Dr. Dr. h. c. E. KLENK zum 70. Geburtstag \\ Von H. Wolf, M. Kochsiek-SChuster und H. LöHR ${ }^{1}$ ) \\ Aus der Universitäts-Kinderklinik" Göttingen (Direktor: Professor Dr. G. Joppicb)
}

(Eingegangen am 3. November 1966)

Die von Kreutz inaugurierte Methode der enzymatischen Bestimmung von freiem Glycerin und Serum-Triglyceriden wird anhand zahlreicher Beispiele in ihren Anwendungsmöglichkeiten in der.Pädiatrie erläutert. Eine eigene Ultramikromodifikation dieser Methode wird speziell für Untersuchungen des Stoffwechsels von freiem Glycerin und von intravenös zugeführten Triglyceriden bei Frühgeborenen ausgearbeitet.

Many examples from paediatrics are given of the use of KREUTz's method for the measurement of free glycerol and serum triglycerides. An ultramicro modification of this method is reported for the investigation of the metabolism of free glycerol and of intravenously administered triglycerides in premature children.

Seit mehreren Jahren wird den Neutralfetten des Serums auch im Bereich der pädiatrischen Forschung und Diagnostik zunehmend Beachtung geschenkt. Eine exakte Bestimmung der Serum-Triglyceride ist vor allem für dynamische Untersuchungen des Stoffwechsels in der Neugeborenenzeit $(1,2)$, zur Kontrolle von Lipid-Veränderungen in Abhängigkeit von der Ernährung $(3,4,5)$. und zu diagnostischen Zwecken erwünscht.

Chemische Verfahren zur Bestimmung des GlycerinAnteils der Triglyceride mit Perjodat $(6,7,8)$ erfordern neben einem beträchtlichen apparativen und zeitlichen Aufwand relativ große Blutmengen. Neutralfettbercchnungen als Differenz aus Esterfettsäuren und Lipoidfettsäuren (9) bzw. aus den Gesamtfettsäuren nach Mikrotitration (10) sind zwar für diagnostische Zwecke genau genug, jedoch für wissenschaftliche Untersuchun1) Teilweise vorgetragen auf dem 1. Weltfettkongreß, Hamburg 1964. gen der Dynamik von Neutralfettveränderungen kaum brauchbar, zumal auch hierbei der Bedarf an Serum für Untersuchungen bei Neugeborenen und Frühgeborenen $z u$ groß ist. Chylomikronenzählung (11) und Ultramikrobestimmung der Gesamtfette (12) lassen nur indirekte Aussagen über die Neutralfette zu und sind wiederum nur für dynamische Untersuchungen des postprandialen Ablaufs der Lipämie brauchbar (13). Hinsichtlich der Spezifität gebührt denjenigen Methoden der Vorzug, bei denen der Glycerinanteil der Triglyceride nach Hydrolyse en zy matiscl bestimmt wird. Enzymatische Glycerinbestimmungen sind von WIELAND (14), HAGEN und HAGEN (15), KREUTZ $(16,17)$, bzw. EgGSTEIN und Kreutz (18) sowie Garland und Randle (19) angegeben worden.

Wir bedienten uns für Untersuchungen des Fettstoffwechsels im Säuglingsalter, bei Frühgeborenen in den ersten Lebenstagen und bei Kindern mit verschiedenen 


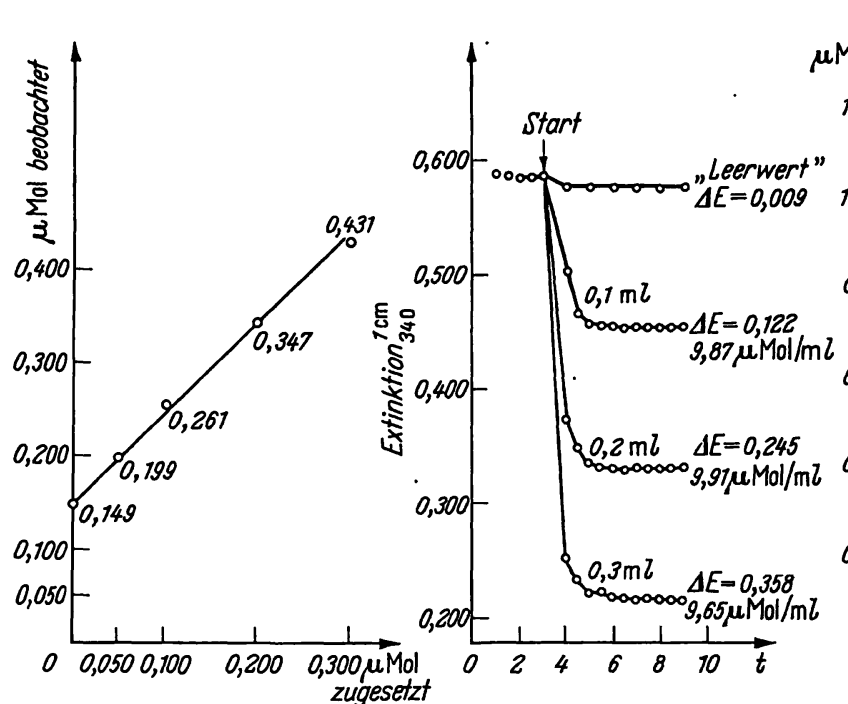

Abb. 1
Abb. 2

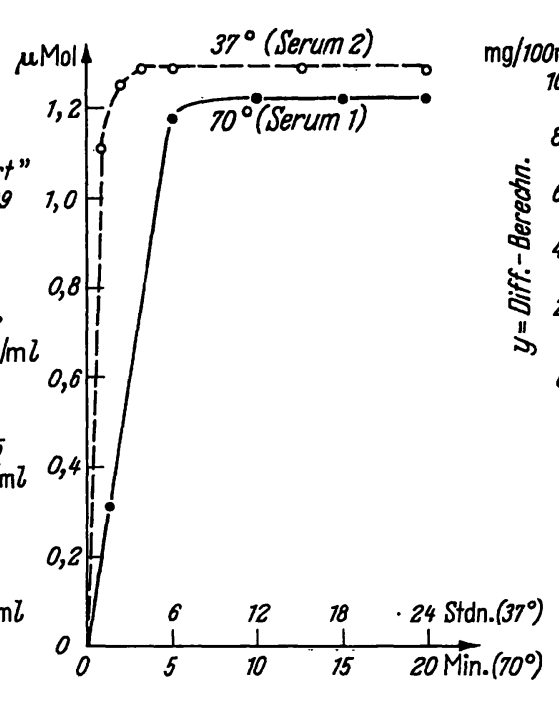

Abb. 3

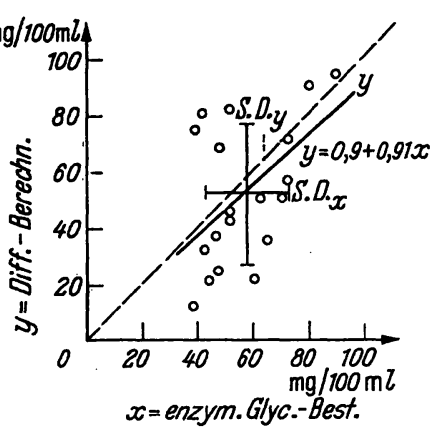

Proportionalität bei Zusatz von Ablauf der enzymatischen Reak- Hydrolyseverlauf von zwei ver- Korrelation zwischen den Resteigenden Mengen Glycerin zum tion bei Einsatz verschiedener Serum (Werte in $\mu \mathrm{Mol}$ ) Mengen Glycerin

Konzentration der eingesetzten Glycerin!ösung $10 \mu \mathrm{Mol} / \mathrm{m} l$ schiedenen Seren bei unterschiedlichen Hydrolysetemperaturen sultaten der Differenzberechnung für Neutralfett und der enzymatischen Glyceridglycerin-Bestimmung

Erkrankungen der von KREUTZ angegebenen Methode, zumal ihre Zuverlässigkeit inzwischen an einem großen Kollektiv erwachsener Patienten erwiesen ist (20). Es handelt sich dabei um eine Bestimmung von Glycerin im zusammengesetzten optischen Test nach folgendem Reaktionsschema (17):

$$
\begin{aligned}
& \text { Glycerin + ATP } \stackrel{\text { flycerokinase }}{\longrightarrow} \text { L-(-)-Glycero-1- } \\
& \text { phosphat + ADP }
\end{aligned}
$$

ADP + Phosphoenolpyruvat $\stackrel{\text { Pyruvatkinase }}{\longrightarrow}$ ATP +

$$
\begin{aligned}
& \text { Pyruvat }+\mathrm{NADH}+\mathrm{H}^{+} \frac{\text { Lactat- }}{\text { Dehydrugenase }} \rightarrow \text { Lactat } \\
& +\mathrm{NAD}^{+}
\end{aligned}
$$$$
\text { Pyruvat }
$$

Die Extinktionsabnahme von $\mathrm{NADH}_{2}$ bei $340 \mathrm{~m} \mu$ bzw. $366 \mathrm{~m} \mu$ nach Start der Reaktion mit Glycerokinase ist direkt proportional der eingesetzten Glycerinmenge.

\section{Methodik}

Mikromethode (nach KREUTZ (16), EgGSTEIN und KREUTZ (18)) Freies Glycerin: Die Bestimmung eifordert 0,1 bis $0,2 \mathrm{~m} /$ Serum für einen Ansatz. Zusatz von Glycerin zum Serum in steigenden Konzentrationen ergibt eine lineare Eichkurve (Abb. 1 u. 2), im Gegensatz zur enzymatischen Bestimmung mit Glycerindehydrogenase (15).

Gesamtglycerin: Bedarf 0,1 bis $0,2 \mathrm{~m} l$ Serum für eine Bestimmung. Nach den von Kreutz (17), Eggstein und Kreutz (18) angegebenen Hydrolysebedingungen ist eine vollständige TriglyceridHydrolyse bei $70^{\circ}$ in $15 \mathrm{Min}$. erfolgt, bei $37^{\circ}$ in $6 \mathrm{Stdn}$. (Abb. 3). Triglyceride: Nach Bestimmung des Glycerins im Serum und im Hydrolysat erfolgt die Berechnung bei einem mittleren Molekulargewicht für Triglyceride (9).nach folgender Formel:

Gesamtglycerin $(\mathrm{mMol} / l)$ - freies Glycerin $(\mathrm{mMol} / l) \cdot 88,5=$ $\mathrm{mg}$ Neutralfett $/ 100 \mathrm{~m} /$ Serum.

Abbildung 4 zeigt eine Korrelationsberechnung, aus der eindeutig anhand der unterschiedlich großen Standardabweichung zwischen

\begin{tabular}{|c|c|c|c|}
\hline $\begin{array}{c}\text { Einsatz } \\
\text { (Mengen in } \mathrm{ml} \text { ) }\end{array}$ & $\begin{array}{c}\text { ml-Zusatz vor } \\
\text { der Hydrolyse } \\
\text { mit KOH }\end{array}$ & $\begin{array}{l}\text { Extinktions- } \\
\text { differenz }(\Delta \mathrm{E}) \\
\text { bei Einsatz v. } \\
0,2 \text { ml Uberstd. } \\
\text { d. Hydrolysats }\end{array}$ & Bemerkungen \\
\hline $\begin{array}{l}0,2 \text { Serum } \\
0,2 \text { Serum }\end{array}$ & $\begin{array}{c}0,2 \text { Na- } \\
\text { Glycerophos- } \\
\text { phat (1 mMolil) }\end{array}$ & $\begin{array}{l}0,103 \\
0,096\end{array}$ & \multirow{2}{*}{$\begin{array}{l}\text { Glycerophosphat } \\
\text { wird beim Glyce- } \\
\text { rintest nicht } \\
\text { erfaßt }\end{array}$} \\
\hline $\begin{array}{l}0,2 \text { Na-Glycero- } \\
\text { phosphat } \\
(1 \mathrm{mMol} / \mathrm{l}) \\
0,2 \text { Dipalmityl- }\end{array}$ & - & 0 & \\
\hline $\begin{array}{l}\text { serin } \\
(1 \mathrm{mMol} / l) \\
0,2 \mathrm{DL}-x- \\
\text { Lecithin } \\
(1 \mathrm{mMol} / l)\end{array}$ & 一 & 0,001 & $\begin{array}{l}\text { bei der angegebe- } \\
\text { nen Arbeitsweise } \\
\text { werden die Phos- } \\
\text { phatide nicht bis } \\
\text { zum Glycerin hy- } \\
\text { drolysiert }\end{array}$ \\
\hline $\begin{array}{l}0,1 \text { Triacetinlösung } \\
(1 \mathrm{mMol} / l)\end{array}$ & $\begin{array}{c}0,2 \mathrm{Na}- \\
\text { phosphat } \\
(0,01 \mathrm{Mol} / \mathrm{l})\end{array}$ & 0,056 & \multirow{2}{*}{$\begin{array}{l}\text { freies Phosphat } \\
\text { stört die Glyce- } \\
\text { rinbestimmung } \\
\text { nicht }\end{array}$} \\
\hline $\begin{array}{l}0,1 \text { Triacetinlösung } \\
(1 \mathrm{mMol} / \mathrm{l})\end{array}$ & - & 0,047 & \\
\hline
\end{tabular}
der Differenzmethode (9) und der enzymatischen Bestimmung die
Tab. 1

Hydrolyseversuche mit verschiedenen Substraten

Überlegenheit der enzymatischen Bestimmung der Triglyceride - ganz abgesehen von dem viel geringeren Verbrauch an Untersuchungsmaterial - hervorgeht. Das bei der Hydrolyse von Phosphatiden freiwerdende $\alpha$-Glycerophosphat stört die Bestimmung nicht. Auch Phosphat-Zusatz zum Serum tleibt ohne Einfluß auf den Ablauf der enzymatischen Reaktion (Tab. 1). Für dynamische Untersuchungen des freeien Glycerins bei Frühgeborenen in den ersten Lebenstagen (21) und für Studien über die Utilisation intravenös zugeführter Fettemulsionen bei unreifen und hypotrophen Neugeborenen waren die benötigten Serummengen noch immer zu groß. Aus diesem Grunde entwickelten wir eine Ultramikromethode.

\section{Ultramikromethode}

Bei reifen Neugeborenen und bei Frühgeborenẹn wurde Kapillarblut durch Fersenstich entnommen und in einem schmalen Zentrifugenröhrchen aus Polyäthylen ( $\mathrm{Fa}$. Beckman/Spinco) oder in einem Glasröhrchen aufgefangen. Die Glasröhrchen (innerer Durchmesser 5-6 mm) wurden zuvor mit Heparinlösung durchgespült und bei $50^{\circ}$ getrocknet. Nach Zentrifugieren wurden mit Konstriktionspipetten $0,02 \mathrm{ml}$ oder $0,05 \mathrm{ml}$ Serum für die Bestimmung von freiem Glycerin und $0,02 \mathrm{~m} l$ Serum für die Bestimmung von Gesamtglycerin entnommen. 
Freies Glycerin: In Kleinküvetten, Schichtdicke $10 \mathrm{~mm}$ (optisches Spezialglas, lichte Breite $2 \mathrm{~mm}$ ), wurden nacheinander pipettiert: $0,5 \mathrm{~m} /$ Testgemisch nach EgGSTEIN und KREUTZ (18)

$0,4 \mathrm{ml} \quad 0,05 \mathrm{M}$ Triäthanolamin-Puffer („TRA“-Puffer), pH 7,6 $0,05 \mathrm{~m} /$ Serum (oder $0,02 \mathrm{~m} /$ Serum).

\section{Das Testgemisclb enthält in $0,5 \mathrm{~m} /$ :}

$2,5 \mu \mathrm{Mol}$ Magnesiumchlorid; $0,5 \mu \mathrm{Mol}$ Phosphoenolpyruvat; $1 \mu \mathrm{Mol}$ Adenosintriphosphat; $10 \mu \mathrm{g}$ Pyruvatkinase; $5 \mu \mathrm{g}$ Lactatdehydrogenase; $0,4 \mu \mathrm{Mol}$ Nicotinamid-Adenin-Dinucleotid red. Nach Mischung mit einem unten abgebogenen PVC-Stab wird die Küvette im Photometer Eppendorf in den Strahlengang gebracht (Filter $\mathrm{Hg} 366 \mathrm{~m} \mu$, Spaltbreite $3 \mathrm{~mm}$ ) und die Registriervorrichtung eingeschaltet (Philips Recordex, Papiervorschub 0,5 cm/Min.). Nach 2-3 Min. werden $2 \mu l$ Glycerokinase-Kristallsuspension (Bochringer Präparat 15746, $1 \mathrm{mg} \mathrm{GK} / 1 \mathrm{ml}$ ) mit PVC Stäbchen dazugegeben und gründlich gemischt. Nach 2-3 Min. ist die enzymatische Reaktion abgelaufen, kenntlich daran, daß die aufgenommene Kurve wieder parallel zur Anfangskurve vor Zugabe von GK verläuft (Abb. 5). Dic Extinktionsabnahme von $\mathrm{NADH}_{2}$

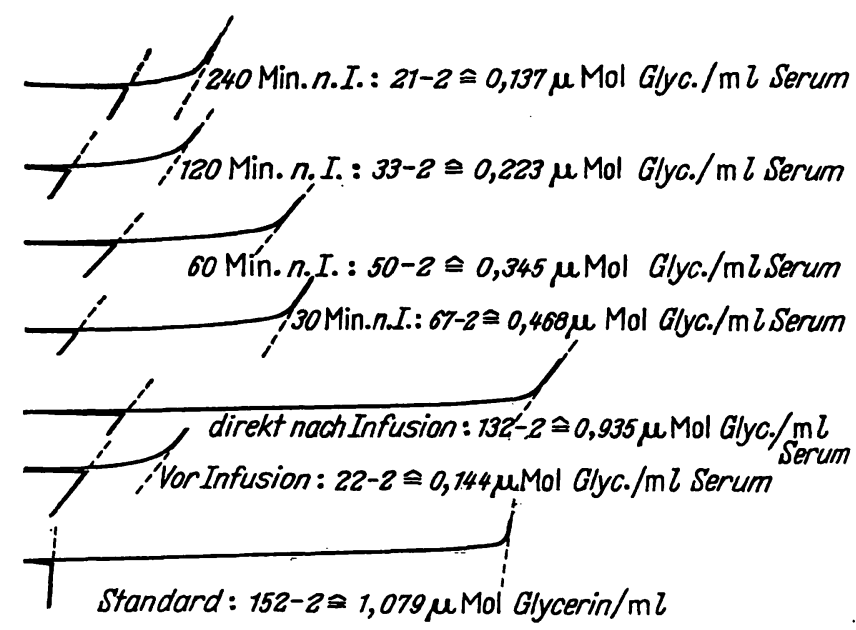

$\{$ Leerwert $2 \mathrm{~mm}$

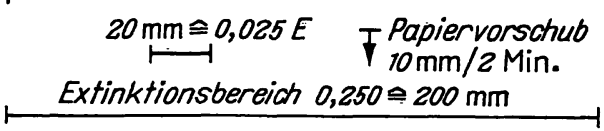

Abb. 5

Registrierung eines Versuchs. Freies Glycerin nach Infusion von Intralipid (Zusammensetzung: $20 \mathrm{~g}$ Sojaöl; 1,2 g Eilecithin; 2,5 g Glycerin; Aqua dest. ad $100 \mathrm{ml}$ ) bei einem frühgeborenen Kind am 2. Lebenstag; Geburtsgewicht $2200 \mathrm{~g}$

ergibt sich aus dem Abstand der Parallelen (20 mm Papierbreite entsprechen einer Extinktionsabnahme von 0,025), Nach Abzug des Leerwertes (statt Serum $0,05 \mathrm{~m} l$ TRA-Puffer) kann mit einem Umrechnungsfaktor die Glycerinmenge in $\mu \mathrm{Mol} / \mathrm{m} l$ Serum nach folgender Formel berechnet werden:

$$
\begin{aligned}
& E\left(\text { Extinktionsbereich) } \cdot V \text { Test } \cdot 0,303^{1}\right)
\end{aligned}
$$

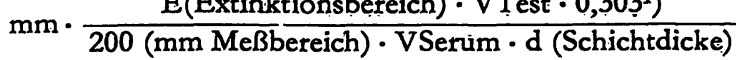

$$
\begin{aligned}
& =\frac{\mathrm{mm} \cdot 0,250 \cdot 0,95 \cdot(\text { bzw. 0,92) } 0,303}{200 \cdot 0,05(\mathrm{~b})} \\
& =\mathrm{mm} \cdot 0,007196 \text { (bzw. 0,01742) } \\
& =\mu \mathrm{Mol} \text { freies Glycerin } / \mathrm{m} / \text { Serum }
\end{aligned}
$$

Gesamtglycerin: In Schliffröhrchen von $8 \mathrm{~mm}$ innerem Durchmesser, $5 \mathrm{~cm}$ Höhe, werden $0,2 \mathrm{~m} / 0,5 \mathrm{~N}$ alkoholische $\mathrm{KOH}$ pipettiert, dazu. mit Konstriktionspipette $0,02 \mathrm{ml}$ Serum. Die Hydrolyse erfolgt

1) Molarer Extinktionskoeffizient $=3,30 \cdot 10^{6} \mathrm{~cm}^{2} / \mathrm{Mol}$ daraus Faktor 0,303.
15 Min. im Wasserbad bei $70^{\circ}$. Nach Abkühlen werden $0,3 \mathrm{ml}$ $0,33 \mathrm{~N}$ Perchlorsäure zugegeben und bei 4000 U./Min. 5 Min. lang zentrifugiert. Für den Test (siehe freies Glycerin) werden 0,1 oder $0,2 \mathrm{~m} /$ Hydrolysat verwendet. TRA-Puffer jedoch 0,3 bzw. $0,4 \mathrm{~m} /$ mit einem $\mathrm{pH}$ von 7,9. Die Küvetten werden nacheinander in den Strahlengang gebracht, die Extinktion (kein Leerschleichl) graphisch registriert. Nach Zugabe von GK wird $1 / 2$ Std. gewartet, bis die Reaktion abgelaufen ist. Der mitgeführte Leerwert wird genau auf die anfangs gemessene Extinktion eingestellt und danach sämtliche Ansätze gemessen (bis zu 10 Ansätzen pro Versuch). Die Differenz zwischen erstem und zweitem Meßwert in $\mathrm{mm}$ wird mit Faktor 0,0492 multipliziert:

$$
\left.\mathrm{mm} \cdot \frac{0,250}{200} \cdot 1^{1}\right) \cdot 0,303 \cdot 10=\mathrm{mm} \cdot \begin{aligned}
& 0,0492=\mu \mathrm{Mol} \\
& \text { Gesamtglycerin } / \mathrm{m} / \text { Serum }
\end{aligned}
$$

Berechnung von Triglyceridglycerin siehe unter "Mikromethode“.

\section{Anwendung}

Erkrankungen im Kindesalter, die mit Veränderungen der Serumlipide einhergehen:

\section{Lipoid-Nepbrose}

Bei der Nephrose sind neben den Phosphatiden und dem Cholesterin auch die Serumneutralfette beträchtlich er-

\begin{tabular}{|c|c|c|c|c|}
\hline Name & Datum & $\begin{array}{l}\text { Gesamt- } \\
\text { Chol. }\end{array}$ & Phosphatide & Triglycer. \\
\hline $\begin{array}{l}\text { E. P. } \\
\text { H. Sch. } \\
\text { F. M. } \\
\text { H. K. }\end{array}$ & $\begin{array}{r}4.2 .63 \\
1.3 .63 \\
26.3 .63 \\
9.4 .63 \\
26.3 .63 \\
11.2 .63 \\
18.2 .63 \ldots \\
3.4 .63\end{array}$ & $\begin{array}{l}618 \\
235 \\
456 \\
159 \\
708 \\
337 \\
420 \\
376\end{array}$ & $\begin{array}{l}578 \\
304 \\
402 \\
200 \\
473 \\
323 \\
387 \\
237\end{array}$ & $\begin{array}{l}647.8 \\
406.5 \\
471.3 \\
170.7 \\
359.5 \\
377.1 \\
516.9 \\
248.3\end{array}$ \\
\hline
\end{tabular}
höht (Tab. 2).

Tab. 2

Cholesterin, Phosphatide und Triglyceride im Serum von Kindern mit Lipoid-Nephrose in verschiedenen Stadien der Erkrankung. Werte in

\section{Hypotbyreose}

Bei Hypothyreosen sind in unbehandeltem Zustand sämtliche Fettfraktionen im Serum erhöht. Bei mit Schilddrüsenhormon behandelten Patienten liegen die Werte für die Fettfraktionen im Normalbereich, im Verlaufe der Behandlung normalisieren sich zuerst die Neutralfette sehr schnell, erst später Phosphatide und Cholesterin (Tab. 3).

Tab. 3

Cholesterin, Phosphatide und Triglyceride im Serum von Kindern mit Hypothyreose (Werte in $\mathrm{mg} / 100 \mathrm{ml}$ )

\begin{tabular}{lccc}
\hline Name & Gesamt-Chol. & Phosphatide & Triglycer. \\
\hline A. M. & 234 & 261 & 386.0 \\
B. J. & 446 & 389 & 37.4 \\
& 162 & 182 & 57.9 \\
\hline
\end{tabular}

A. M. unbehandelt; B. J. mit „Thybon" behandelt.

\section{Congenitale Lebersteatose}

Wir konnten eine Familie untersuchen, in der Vater und Tochter an einer congenitalen Lebersteatose vom Cholesterin-Typ litten (leberbioptischer Nachweis bei dem Kind). Cholesterin und Phosphatide im Serum

1) Die Serumverdünnung bei Verwendung von $0,2 \mathrm{~m} /$ Hydrolysat im Meßansatz beträgt $1: 13$ bei Einsatz von $0,02 \mathrm{ml}$ Serum $\mathrm{zu}_{\mathbf{r}}$ Hydrolyse, bei Verwendung von $0,1 \mathrm{ml}$ Hydrolysat $1: 26$. 
Tab. 4

Cholesterin, Phosphatide und Triglyceride im Serum einer Familie, in der 2 Mitglieder eine congenitale Lebersteatose vom Cholesterin-Typ aufweisen. Werte in $\mathrm{mg} / 100 \mathrm{ml}$

\begin{tabular}{llccc}
\hline Name & Datum & $\begin{array}{c}\text { Gesamt- } \\
\text { Chol. }\end{array}$ & Phosphatide & Triglycer. \\
\hline Elke N. & 23.1. & 434 & 370 & 412.5 \\
Elke N. & 13.2. & 401 & 356 & 340.9 \\
Elke N. & $\left.17.2 .{ }^{1}\right)$ & 500 & 354 & 270.2 \\
\hline Elke N. & 9.4. & 336 & 362 & 258.9 \\
Elis. N. & 9.4. & 213 & 255 & 57.6 \\
Ralf N. & 9.4. & 192 & 243 & 93.1 \\
Wolf N. & 9.4. & 145 & 219 & 62.1 \\
Vater N. & 9.4. & 311 & 322 & 246.2 \\
Mutter N. & 9.4. & 160 & 241 & 61.2 \\
Großmutter & 9.4. & 254 & 322 & 124.3 \\
väterl. N. & 9.4. & & &
\end{tabular}

2) nach fettfreier Ernährung.

waren bei Vater und Tochter mäßig erhöht, die Neutralfette lagen deutlich über der Norm. Die übrigen Familienmitglieder hatten normale Serumlipidwerte (Tab. 4).

\section{Sonstige Erkrankungen}

Bei gut mit Insulin eingestellten Diabetes mellitusPatienten sind die Neutralfettkonzentrationen im Serum nicht erhöht. Bei mäßig guter Einstellung können speziell Neutralfette erhöht sein; weitere Untersuchungen zu diesem Problem sind in Vorbereitung. Bei einem 5jährigen Jungen ${ }^{1}$ ) mit einer essentiellen Hypertri-

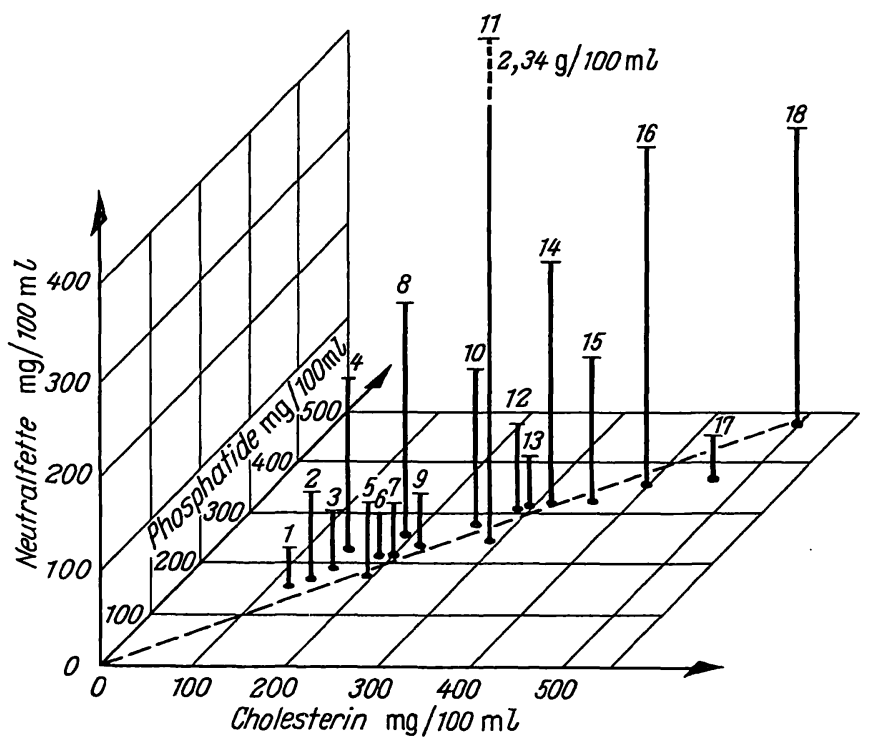

Abb. 6

Blutfette bei verschiedenen Krankheiten im Kindesalter. Die Neutralfette sind durch die Säulenhöhe dargestellt. Säulenfußpunkte entsprechen der Relation Cholesterin: Phosphatide Erklärung dor Zahlen: 1, 3 = Coeliakie; 2, $5=$ Diabetes mellitus, gut eingestellt; $6,7,9=$ Normalwerte für Säuglinge; $4,8=$ Pankreatitis; $10=$ Diabetes mellitus, schlecht eingestellt; 11 = essentielle Hypertriglyceridämie; $12=$ Normalwert für Erwachsene; 14, $16=$ Lebersteatose '(Vater u. Tochter); $15,18=$ Nephrose; $13,17=$ Hypo-

1) Patient aus dem St. Anna-Stift, Ludwigshafen/Rhein (Chefarzt: Professor Dr. Karte). glyceridämie (mit chylösen Gelenk- und Pleuraergüssen) fanden wir Werte für Triglyceride zwischen 2,21 und $2,95 \mathrm{~g} / 100 \mathrm{ml}$ Serum. Ein Patient mit Pankreatitis wies hohe Cholesterin- und Phosphatidwerte im Serum auf, die Neutralfette waren normal. Patienten mit Coeliakie hatten in der Regel einen sehr niedrigen Neutralfettgehalt im Serum bei ebenfalls erniedrigtem Cholesterin und Phosphatiden.

Einen ausgewählten Teil unserer Befunde zeigt die Abbildung 6, in der gleichzeitig die bei nahezu allen Erkrankungen bestehende strenge Korrelation zwischen Cholesterin und Phosphatiden zu erkennen ist. Die Neutralfette dagegen nehmen eine Sonderstellung ein.

\section{Fettelimination bei Friibgeborenen}

Bei vier frühgeborenen Kindern wurde eine Fettemulsion am 1. und am 7. Lebenstag intravenös appliziert (Lipofundin $=20,0 \mathrm{~g}$ Baumwollsaatöl, 1,5 g Sojaphosphatid, 5,0 g Sorbit, Vitamin E, aqua dest. ad 100,0). Die Kinder erhielten in $5 \mathrm{Min}$. eine Testmenge von $0,5 \mathrm{~g} / \mathrm{kg}$ Körpergewicht. In Abständen von $0 ; 30 ; 60$;

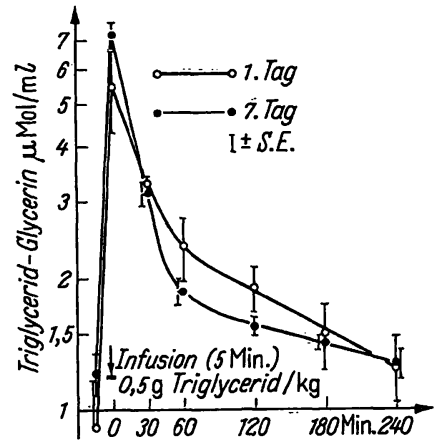

Abb. 7

Fettinfusion bei 4 Frühgeborenen am 1. und 7. Lebenstag Die Kinder erhielten jeweils eine Testdosis von $0,5 \mathrm{~g}$ Fett/kg Körpergewicht innerhalb 5 Min. mit Perfusor (Fa. B. Braun Apparatebau, Melsungen) i. v. infundiert

120; 180 und 240 Min. nach Ende der Infusion wurden im Serum Triglyceride nach der angegebenen Ultramikromethode bestimmt. Abbildung 7 zeigt, daß schon am 7. Lebenstag die Eliminations-Halbwertszeit für die infundierte Fettemulsion deutlich gegenüber dem 1. Tag abgenommen hat. Frühgeborene am 1. Lebenstag utilisieren bzw. speichern (?) das intravenös zugeführte Fett langsamer als 7 Tage alte Frühgeborene.

Die enzymatische Triglycerid-Bestimmung erlaubt erstmals genauere Einblicke in den Stoffwechsel von freiem Glycerin $(22,23)$ speziell bei Neugeborenen und von Triglyceriden bei Säuglingen (24) und Kindern. Bisher liegen nur wenige Untersuchungen der Triglyceride bei Diabetes, Nephrose, Coeliakie und Hypothyreose im Kindesalter vor. Weitere Studien sind erforderlich.

\section{Literatur}

1. Rafstedt, S., Acta paediatr. (Üppsala) 44, Suppl. 102 (1955). 2. Novak, M., V. Melichar, P. Hahi, und O. Koldovsky, Physiol. Bohemoslov. 10, 488 (1961). - 3. SweEney, M. J., J. N. Etteldorf, W. T. Dobbins, B. Somervill, R. Fisher und C.
Ferrell, Pediatrics 27, 765 (1961). - 4. Sweeney, M. J., J. N. Etteldorf, L. J. Troop, D. L. Timma und E. L. WrenN, J. clin. Invest. 42, 1 (1963). - 5. WpLF, H. und H. LöHR, Mschr. Kinderhk. 113, 310 (1965). - 6. CARLSON, L. A. und L. B. WAD- 
STRÖM, Clin. chim. Acta 4, 197 (1959). - 7. VAN HaNdel, E. und D. B. Ziversmit, J. Lab. clin. Med. 50, 152 (1957). - 8. Randrup, A., Scand. J. clin. Lab. Invest. 12, 1 (1960). - 9. EgGstein, M., Klin. Wschr. 43, 1031 (1965). - 10. Albrink, M. J., J. Lipid Res. 1, 53 (1959). - 11. Frazer, A. C. und H. C. Stewart, J. Physiol. 95, 21 (1939). - 12. ZölLNER, N. und K. KIRsCH, Zschr. ges. exp. Med. 135, 545 (1962). - 13. LöHR, H., J. STumm und H. Wolf, Med. Ernährg. 6, 8 (1965). - 14. Wieland, O., Biochem. Z. 329, 313 (1957). - 15. HAGEN, J. H. und P. B. Hagen, Canad. J. Biochem. Physiol. 40, 1129 (1962). - 16.
KREUTz, F. H., Klin. Wschr. 40, 362 (1962). - 17. KREUTZ, F. H.' 5. Intern. Congress of Clinical Chemistry, Detroit 1963. - 18. Eggstern, M. und F. H. Kreutz, Klin. Wschr. 44, 262 (1966). 19. Garland, P. B. und P. J. RandLe, Nature (London) 196, 987 (1962). - 20. Eggstein, M., Klin. Wschr. 44, 267 (1966). - 21. Melichar, V. und H. Wolf, Biol. Neonat. (Basel) 11, 50 (1967). - 22. Novak, M., V. Melichar und Biol. Neonat. (Basel) 8, 253 (1965). - 23. Persson, B. und J. Gentz, Acta paediatr. (Uppsala) 55, 353 (1966). - 24. Schuster, M., Dissert. Göttingen (1963).

\title{
Serumextraktion und dünnschichtchromatographische Trennung zirkulierender Jodaminosäuren
}

\author{
Vergleich der Ergebnisse durch chemische und nucleonische Nachweismethoden
}

\author{
Von E. Zappr und G. Hoppe
}

Aus der 1. Medizinischen Abteilung (Chefarzt: Prof. Dr. K. H. Pfeffer) und der Strablenabteilung (Chefarzt: Prof. Dr. W. Frombold) des Städt. Auguste-Viktoria Krankenbauses, Berlin

(Eingegangen am 19. Oktober 1966)

Es wird ein kombiniertes Verfahren beschrieben, das durch alkoholische Extraktion aus dem Serum und durch dünnschichtchromatographische Trennung die chemische Identifikation verschiedener zirkulierender Jodaminosäuren, angeblich Jodtyrosine, gestattet. Die gleichzeitige Anwendung von Radiojod erlaubt aber den Nachweis markierter Jodthyronine in den gleichen Chromatogrammen, die chemisch nicht zu erfassen sind. Nach der Diskussion der Ergebnisse wird auf die Nutzbarkeit der Methode hingewiesen, klinisch-pathologische Aspekte zu untersuchen.

A method is described for the chemical identification of different circulating iodo-amino acids, presumably iodo-tyrosines; alcoholic extraktion of the serum is followed by thin layer chromatography. If radioactive iodine is also used, labelled iodothyronines, which cannot be detected chemically, can then be detected on the same chromatograms. The results are discussed, and the suitability of the method for the study of clinical-pathological problems is indicated.

Die geringen Serumkonzentrationen des Thyroxin und anderen jodierter phenolischer Aminosäuren („JPA") erschweren den Nachweis und die Identifizierung dieser Verbindungen. Sie wurde bisher am häufigsten versucht durch Anwendung von Radiojod. Die Verwendung radioaktiven Jods hat aber, abgesehen von den Einwänden die gegen seine Anwendung in hohen Dosen beim Menschen bestehen, methodische Fehlermöglichkeiten. So bleibt $z$. B. seit den ersten Markierungsversuchen der Schilddrüsenhormone in den fünfziger Jahren die Frage offen, ob die dargestellten Substanzen nicht teilweise Artefakte sind. Diese könnten durch die Bestrahlung der Schilddrüse oder während langdauernder chromatographischer Verfahren nachträglich durch die ionisierenden Strahlen entstanden sein (1-6). Die Jodaufnahme der Schilddrüse und der Einbau des Radiojods in die verschiedenen organischen Fraktionen sind direkt abhängig von dem biologischen Zustand des Parenchyms der Drüse. Die Markierungsrate der JPA ist unterschiedlich und darum eine qualitative oder gar quantitative Aussagemöglichkeit dieser Methoden sehr begrenzt.

Die ersten indirekten chemischen Aussagen über die Natur der im Plasma zirkulierenden Jodverbindungen zeigten eine nahezu gleichmäßige Aufteilung in Jodthyronine und Jodtyrosine (7). Spätere Untersuchungen, die schon mit Radiojod durchgeführt wurden, erbrachten dagegen übereinstimmend den fast ausschließlichen Nachweis von Thyroxin. Später wurden auch Trijodthyronin im Serum nachgewiesen und in den letzten Jahren mit zunehmender Häufigkeit Dijod- und Monojodtyrosin (8-12). Die Anwesenheit dieser Substanzen wurde jedoch meist als eine Besonderheit von diagnostischem Wert für verschiedene Schilddrüsenerkrankungen betrachtet. So wurde der Nachweis von Trijodthyronin als ein Zeichen für Hyperthyreose angesehen $(13,14)$. StANsURY begründete ebenfalls die Diagnose der Jodfehlverwertung bei bestimmten Fällen der Hypothyreose mit dem Vorhandensein von jodierten Tyrosinen im Serum $(15,16)$. Einige Autoren waren aber der Ansicht, daß diese Substanzen normale Komponenten des Plasmas wären, die aus verschiedenen Gründen (unterschiedliches „turn over“, unterschiedliche Verdünnung der Substanzen in ihren entsprechenden „pools“, geringerer Jodanteil der Moleküle usw.) nur schwer oder überhaupt nicht mit Radiojod markiert werden könnten $(17,18)$.

WERNER und BLOCK führten 1959 vergleichende Untersuchungen durch, wobei die JPA chemisch und durch Radioaktivität bestimmt wurden. Sie konnten dabei zum ersten Male eine auffällige Diskrepanz zwischen den 